\title{
Mild volume acute normovolemic hemodilution is associated with lower intraoperative transfusion and postoperative pulmonary infection in patients undergoing cardiac surgery - a retrospective, propensity matching study
}

\author{
Zhen-feng Zhou ${ }^{1}$, Xiu-ping Jia ${ }^{1,2}$, Kai Sun ${ }^{1}$, Feng-jiang Zhang ${ }^{1}$, Li-na Yu' ${ }^{1}$, Tian Xing ${ }^{1}$ and Min Yan ${ }^{1 *}$
}

\begin{abstract}
Background: Perioperative allogenic transfusion is required in almost 50\% of patients undergoing cardiac surgery and is associated with higher risk of mortality and morbidity (Xue et al., Lancet 387:1905, 2016; Ferraris et al., Ann Thorac Surg 91:944-82, 2011). Acute normovolemic hemodilution (ANH) is recommended as a potential strategy during cardiac surgery, but the blood conservation effect and the degree of ANH was still controversial. There is also an increasing concern about the improved outcomes associated with ANH. Therefore, a better understanding of the effect of mild volume ANH during cardiac surgery is urgently needed.
\end{abstract}

Methods: This retrospective study included 2058 patients who underwent cardiac surgery between 2010 and 2015. The study population was split into two groups (with and without mild volume ANH). Propensity score adjustment analysis was applied. We reported the association between the use of mild volume ANH and perioperative outcomes.

Results: A total of 1289 patients were identified. ANH was performed in 358 patients, and the remaining 931 patients did not receive any ANH. Five hundred of the total patients (38.8\%) received perioperative RBC transfusions, $10 \%$ (129/1289) of patients received platelet, and 56.4\% (727/1289) of patients received fresh frozen plasma transfusions. Mild volume ANH administration was significantly associated with decreased intraoperative RBC transfuse rate ( $8.5 \%$ vs. $14.4 \% ; p=0.013)$, number of $\operatorname{RBC}$ units $(p=0.019)$, and decreased postoperative pulmonary infection (6.8 vs. $11.3 \% ; p=0.036)$ during cardiac surgery. However, there was no significant difference regarding intraoperative fresh frozen plasma (FFP) and platelet concentrate transfusions, as well as postoperative and total perioperative allogeneic transfusions. Furthermore, there was no significant difference regarding postoperative outcomes including mortality, prolonged wound healing, stroke, atrial fibrillation, reoperation for postoperative bleeding and acute kidney injury. There was also no difference in postoperative ventilation time, length of ICU and hospital stay.

(Continued on next page)

\footnotetext{
* Correspondence: zryanmin@zju.edu.cn

${ }^{1}$ Department of Anesthesiology, Second Affiliated Hospital, School of

Medicine, Zhejiang University, Zhejiang Province, China

Full list of author information is available at the end of the article
} 
(Continued from previous page)

Conclusion: Based on the 5-year experience of mild volume ANH in cardiac surgeries with CPB in our large retrospective cohort, mild volume ANH was associated with decreased intraoperative RBC transfusion and postoperative pulmonary infection in Chinese patients undergoing cardiac surgery. However, there was no significant difference regarding postoperative and total perioperative allogeneic transfusions.

Keywords: Hemodilution, Transfusion, Complication, Cardiac surgery

\section{Background}

In China, blood shortage is now becoming an important public health concern, and the lack of adequate blood donation is considered to be the main cause [1]. Perioperative allogenic transfusion is required in about $50 \%$ of patients undergoing cardiac surgery [2], but it is associated with higher risk of mortality and morbidity (infection, lung injury, renal failure, and stroke) [3-5]. Hence, many blood conservation techniques are recommended of which acute normovolemic hemodilution (ANH) may be considered as an adjuvant in appropriate patients [2].

Thus far, no consensus has been achieved in the results of published studies on ANH. Many trials have confirmed the positive effects of ANH in reducing perioperative allogeneic transfusions [6,7]; however, other studies have reported negative effects $[8,9]$. Another important debated point is the degree of ANH performed. Some authors consider that only a large volume of ANH is useful or effective in minimizing the need for allogeneic transfusions [7, 10]; however, Kahraman et al. observed no differences between the effect of mild and high volume of ANH on postoperative bleeding and perioperative blood transfusions [11]. Furthermore, there may be a risk of performing moderate or severe ANH in patients with a lower preoperative hematocrit level in cardiac surgery with cardiopulmonary bypass (CPB) which would lead to hemodilution [12].

There is also an increasing concern about the improved outcomes associated with ANH [7, 13, 14]; the safety of ANH still remains uncertain [15]. We performed this study to assess the relationship between mild volume $\mathrm{ANH}$, perioperative transfusions, and outcomes in Chinese patients undergoing cardiac surgery.

\section{Methods}

\section{Study population and design}

The present study was a single center, retrospective study which was approved by the Ethics Committee of Zhejiang University (Hangzhou, China; No.2016-021), with patient consent waived. A total of 2058 consecutive adult patients underwent cardiac surgeries with $\mathrm{CPB}$ from January 1, 2010, to December 31, 2015 and ANH was performed throughout all 5 years. The following exclusion criteria were applied as they were unsuitable for ANH: (1) low weight (weight $<50 \mathrm{~kg}$ for men and $<45 \mathrm{~kg}$ for women); (2) ASA (American Standards Association) class V; (3) emergent or redo surgery; (4) previous shock or left ventricular ejection fraction (LVEF) $<35 \%$; (5) previous coexistent disease (endocarditis; a history of myocardial infarction in the previous 30 days; chronic obstructive pulmonary disease [COPD]; anemia; chronic kidney disease [CKD]; serum albumin level [ALB] $<25$ g/ L); (6) international normalized ratio (INR) $>1.5$ or platelet count $<100 \times 10^{3} / \mathrm{mm}^{3}$; (7) acquired or inherited bleeding disorders; (8) cancer disease. Then the study population was devided into $\mathrm{ANH}$ group (with $\mathrm{ANH}$ ) and non-ANH group (without ANH).

Perioperative medical record information including demographic characteristics, patient history (preoperative medications, coexistent disease and other risk factors), operative data, perioperative allogeneic transfusions, and postoperative complication were retrieved from the hospital medical records during the entire hospitalization period regardless of days. An independent investigator reviewed all data.

\section{ANH techniques and transfusion strategy}

General anesthesia and standard monitoring were performed. According to institutional standards, body temperature of patients was maintained at $30{ }^{\circ} \mathrm{C}$ during $\mathrm{CPB}$. When the surgery was finished, patients were rewarmed to $37{ }^{\circ} \mathrm{C}$ and weaned from $\mathrm{CPB}$. ANH was performed after induction of anesthesia and before heparinization for CPB [7]. The mild volume ANH [8] was performed with $5-8 \mathrm{ml} / \mathrm{kg}$ of whole blood withdrawn from an introducer of Fast-Cath catheter (St. Jude Medical, USA) into standard citrate phosphate-dextrose collection bags by gravity. The removed blood volume was simultaneously replaced with an equal volume of hydroxyethyl starch solutions (6\%Haes 130/0.4; Fresenius Kabi, Stans, Switzerland). Collected blood was kept at $4{ }^{\circ} \mathrm{C}$ temperature refrigerator without shaker.

Transfusion criteria were the same in both groups. The cell saver was routinely performed, the administration of antifibrinolytics was apllied according to the anesthetist's judgment, and additional blood transfusions were deliberately determined by the surgery team caring of the patients. Blood transfusions were usually carried out when the following criteria were met [2] and other additional decisions were made 
according to the patient's clinical condition. Red blood cells (RBC) were transfused when hemoglobin concentrations was $<6 \mathrm{~g} / \mathrm{dL}$ during $\mathrm{CPB}$ and $<7 \mathrm{~g} / \mathrm{dL}$ after $\mathrm{CPB}$. When international normalized ratio (INR) $>1.4$ or activated partial prothrombin time $(\mathrm{aPTT})>50 \mathrm{~s}$ or $\mathrm{R}$ time $>10 \mathrm{~min}$ in Thromboelastometry test (TEG), prothrombin complex concentrate (PCC) was administered (20-30 IU/ kg). If the above mentioned parameters prolongation did not respond to administration of PCC or there occured hypovolemia, Fresh frozen plasma (FFP) was transfused $(10-15 \mathrm{~mL} / \mathrm{kg})$. Platelets were transfused when platelets count $<50 \times 10^{9} / \mathrm{L}$ and fibrinogen concentrate $(\mathrm{Fb})$ was administered of $25-$ $50 \mathrm{mg} / \mathrm{kg}$ when $\mathrm{Fb}<1.5 \mathrm{~g} / \mathrm{L}$. Activated recombinant factor VII (rVIIa) was considered of $90 \mathrm{ug} / \mathrm{kg}$ as rescue therapy if the bleeding still existed while INR $<1.4$, aPTT $<50 \mathrm{~s}, \mathrm{Fb}>2 \mathrm{~g} / \mathrm{L}$, platelet count $>100 \times 10^{9} / \mathrm{L}$. When transfusion criteria were met during the surgery, the withdrawn blood was reinfused firstly. If transfusion criteria were not met till the end of surgery, the withdrawn blood was also reinfused before the patients were transferred out of the operation room. The reinfusion of withdrawn blood was performed within $6 \mathrm{~h}$. Blood recovered from the extracorporeal circuit system (pumped blood) was not accounted into the volume of the blood transfusions.

\section{Perioperative endpoints}

The end points occurred during the hospitalization were recorded in patient medical documents. The primary endpoint was any perioperative transfusions. Other endpoints included in-hospital mortality (intraoperation and postoperation death, which were defined as death in the operation room and death after operation up to discharge seperately), morbidity, duration of mechanical ventilation, length of ICU (intensive care unit) stay, length of hospital stay (LOS) and hemostatic drugs adminstration. Hospital morbidities included the following: (1) pulmonary infection was confirmed based on symptoms (fever and expectoration) and laboratory evidence (culture-positive sputum, chest roentgenogram, or computed tomography findings) by a physician reviewing the medical data [16]; (2) prolonged wound healing which was defined as $>7$ days for wound healing; (3) stroke which was a new ischemic cerebrovascular accident confirmed by radiological evidence with a neurological deficit lasting for more than $24 \mathrm{~h}$ and with radiological evidence [17]; (4) new-onset atrial fibrillation (AF) [18]; (5) re-exploration for bleeding during hospitalization; (6) acute kidney injury (AKI), defined by Improving Global Outcomes criteria [19]: increase in serum creatinine $(\mathrm{Cr})$ by $\geq 26.5 \mu \mathrm{mol} / \mathrm{l}$ within $48 \mathrm{~h}$; or Increase in $\mathrm{Cr}$ to $\geq 1.5$ times baseline within the previous 7 days. AKI is staged for severity according to the following criteria: stage $1(\mathrm{Cr} \geq 26.5 \mu \mathrm{mol} / \mathrm{L}$ above baseline or 1.5-1.9 times baseline), stage 2 (Cr 2.0-2.9 times baseline), or stage 3 ( $\mathrm{Cr} \geq 3$ times baseline or postoperative $\mathrm{Cr}$ of $\geq 353.6 \mu \mathrm{mol} / \mathrm{L}$, or initiation of renal replacement therapy).

\section{Statistical methods}

Descriptive analyses of variables were used to summarize data. The normal distributed variables were expressed as mean \pm standard deviation (SD) and compared with student $t$-test. Abnormal continuous variables were expressed as median (interquartile range (IQR)) and evaluated with Mann-Whitney $U$-test.respectively. Chi-square or Fisher's exact test was used to compare proportions between the two groups. Missing continuous variables of baseline parameters were less than $10 \%$ and were replaced by median in Table 1. All reported $p$ values were two sided, and values of $p<0.05$ were considered to be statistically significant. Statistical analysis was performed with SPSS version 18.

To minimize the effect of selection bias on outcomes, we used propensity score matching for clinical characteristics to reduce distortion by confounding factors. Using propensity score analysis by the method of nearest-neighbor matching, we generated a set of matched cases (ANH) and controls (non-ANH). According to the propensity score matching, 354 pairs of patients were identified for postoperative analysis. A propensity score was generated for each patient from a multivariable logistic regression model on the basis of the covariates using clinical characteristics data (Table 1) from the institutional registry as independent variables, with treatment type (ANH vs. Non-ANH) as a binary dependent variable. We matched patients using a greedymatching algorithm with a caliper width of 0.1 of the estimated propensity score. A matching ratio of 1:1 was used. We evaluated post match covariate balance by comparing the balance of baseline covariates between patients with $\mathrm{ANH}$ and non-ANH before and after matching using absolute standardized differences [20].

\section{Results}

\section{Baseline parameters}

A total of 1289 patients were identified and divided into two groups: patients who received ANH (ANH group, $n=$ $358,27.8 \%$ ) and those who did not receive ANH (nonANH group, $n=931,72.2 \%$ ) during the operative period (Fig. 1). The mean removed blood was $346 \mathrm{~mL}$ in the $\mathrm{ANH}$ group. The average age of the study population was 51 years, $52.1 \%$ were females, $71.8 \%$ with ASA class III, $5.7 \%$ with ASA class IV, and $24.5 \%$ had NYHA class III and IV. A total of $38.7 \%$ of the total patients underwent complex cardiac (combined coronary artery bypass graft surgery and valve surgery or multi-valve surgery) or aortic surgery (Aortic dissections, type $\mathrm{A}$ and $\mathrm{B}$, thoracic aortic aneurysms or Aortic valve surgery with ascending aortic replacement). 
Table 1 Demographic and Clinical characteristics of the two study groups before and after propensity score matching

\begin{tabular}{|c|c|c|c|c|c|c|}
\hline \multirow{3}{*}{ Preoperative characteristics } & \multicolumn{3}{|l|}{ Entire sample } & \multicolumn{3}{|c|}{ Propensity-matched group } \\
\hline & \multicolumn{2}{|l|}{$\overline{\mathrm{ANH}}$} & \multirow[t]{2}{*}{$p$-value } & \multicolumn{2}{|l|}{$\overline{\mathrm{ANH}}$} & \multirow[t]{2}{*}{$p$-value } \\
\hline & Yes $(n=358)$ & No $(n=931)$ & & Yes $(n=354)$ & No $(n=354)$ & \\
\hline Age [median (SD); yr] & $50 \pm 12$ & $51 \pm 13$ & 0.139 & $50 \pm 12$ & $50 \pm 13$ & 0.866 \\
\hline Male/female, no.(\%) & $224 / 134(62.6 \%)$ & $394 / 537(42.3 \%)$ & $<0.001$ & $220 / 134(62.1 \%)$ & $222 / 132(62.7 \%)$ & 0.877 \\
\hline Height [median (SD); cm] & $164 \pm 7$ & $162 \pm 7$ & $<0.001$ & $164 \pm 7$ & $164 \pm 7$ & 0.761 \\
\hline Weight [mean (SD); kg] & $63 \pm 10$ & $60 \pm 10$ & $<0.001$ & $63 \pm 10$ & $62 \pm 10$ & 0.580 \\
\hline Estimated blood volume [mean (SD); mL] & $4298 \pm 779$ & $4045 \pm 722$ & $<0.001$ & $4285 \pm 765$ & $4258 \pm 750$ & 0.636 \\
\hline ASA, no. (\%) & & & 0.070 & & & 0.230 \\
\hline । & $1(0.3 \%)$ & $4(0.4)$ & & $1(0.3 \%)$ & $3(0.8 \%)$ & \\
\hline$\|$ & 79 (22.1\%) & $206(22.1 \%)$ & & 79 (22.3\%) & 77 (21.8\%) & \\
\hline III & $248(69.3 \%)$ & $678(72.8 \%)$ & & $244(68.9 \%)$ & $256(72.3 \%)$ & \\
\hline IV & $30(8.4 \%)$ & $43(46 \%)$ & & $30(8.5 \%)$ & $18(5.1 \%)$ & \\
\hline NYHA class III/IV, no.(\%) & $83(23.2 \%)$ & $233(25 \%)$ & 0.491 & $81(22.9 \%)$ & $75(21.2 \%)$ & 0.586 \\
\hline History of smoking, no. (\%) & $108(30.2 \%)$ & $204(21.9 \%)$ & 0.002 & $108(30.5 \%)$ & $100(28.2 \%)$ & 0.509 \\
\hline \multicolumn{7}{|l|}{ Coexistent disease } \\
\hline AF, no. (\%) & $81(22.6 \%)$ & $222(23.8 \%)$ & 0.644 & $80(22.6 \%)$ & $82(23.2 \%)$ & 0.858 \\
\hline Hypertension, no. (\%) & 75 (20.9\%) & $209(22.4 \%)$ & 0.561 & 74 (20.9\%) & 79 (22.3\%) & 0.648 \\
\hline Diabetes, no. (\%) & $17(4.7 \%)$ & $63(6.8 \%)$ & 0.179 & $17(4.8 \%)$ & $18(5.1 \%)$ & 0.862 \\
\hline HLP, no. (\%) & $5(1.4 \%)$ & $6(0.6 \%)$ & 0.191 & $5(1.4 \%)$ & $2(0.6 \%)$ & 0.451 \\
\hline Cerebrovascular disease, no. (\%) & $16(4.5)$ & $37(4.0)$ & 0.688 & $16(4.5)$ & $16(4.5)$ & 1.000 \\
\hline \multicolumn{7}{|l|}{ Preoperative Medication } \\
\hline ACEl and ARB, no. (\%) & $28(7.8 \%)$ & $77(8.3 \%)$ & 0.792 & $28(7.9 \%)$ & $29(8.2 \%)$ & 0.890 \\
\hline$\beta$-blockers, no. (\%) & $19(5.3 \%)$ & $66(7.1 \%)$ & 0.248 & $19(5.4 \%)$ & $22(6.2 \%)$ & 0.629 \\
\hline Calcium Channel Blockers, no. (\%) & $25(7.0 \%)$ & $71(7.6 \%)$ & 0.694 & $24(6.8 \%)$ & $19(5.4 \%)$ & 0.431 \\
\hline Diuretics, no. (\%) & $16(4.5 \%)$ & $70(7.5 \%)$ & 0.049 & $16(4.5 \%)$ & $13(3.7 \%)$ & 0.569 \\
\hline \multicolumn{7}{|l|}{ Preoperative laboratory examination } \\
\hline T-ch [median (SD); mmol/L] & $4.5 \pm 1.0$ & $4.4 \pm 1.1$ & 0.178 & $4.5 \pm 1.0$ & $4.4 \pm 1.1$ & 0.305 \\
\hline $\mathrm{Cr}$ [median (SD); umol/L] & $70 \pm 15$ & $67 \pm 16$ & $<0.001$ & $70 \pm 15$ & $70 \pm 17$ & 0.976 \\
\hline ALB [median (SD); g/L] & $42 \pm 4$ & $42 \pm 4$ & 0.182 & $42 \pm 4$ & $42 \pm 4$ & 0.535 \\
\hline $\mathrm{HCT}$ [median (SD); \%] & $42 \pm 5$ & $40 \pm 4$ & $<0.001$ & $42 \pm 4$ & $42 \pm 4$ & 0.918 \\
\hline Propensity score [median (SD)] & $0.33 \pm 0.12$ & $0.26 \pm 0.11$ & $<0.001$ & $0.32 \pm 0.12$ & $0.32 \pm 0.11$ & 0.840 \\
\hline
\end{tabular}

\#: Fisher's exact test was used; BMI body mass index, ASA American Society of Anesthesiologists, NYHA New York Heart Association, AF atrial fibrillation, HLP hyperlipidaemia, CKD chronic kidney disease, COPD chronic obstructive pulmonary disease, MI myocardial infarction in 30 days before operation, $A R B$ angiotensin receptor blockers, ACEl angiotensin converting enzyme inhibitors, LVEF left ventricular ejection fraction, $T$-ch serum cholesterol, Cr serum creatinine, $A L B$ albumin, HCT hematocrit

The clinical characteristics of the two matched groups (with and without $\mathrm{ANH}$ ) extracted by propensity analysis were presented in Table 1. According to the standardized difference, covariate balance between the matched pairs was confirmed. An additional data material file shows in detail (see Additional file 1).

\section{Operative characteristics}

As ANH technique was performed, the blood hematocrit was lower in the ANH group $(p<0.05)$. The ANH group had more intraoperative cristalloids and colloids volume (2272 \pm 610 vs. $2140 \pm 770) \mathrm{mL} ; p=0.011$ ), but there was no significant difference in blood loss, urine output, and pump blood between the two groups. No significant difference was observed between the two matched groups regarding operative characteristics including surgery type, the number of intra-aortic balloon pump (IABA) utilized, cardiopulmonary bypass time, anesthesia time, surgery time, calcium content, and the blood $\mathrm{pH}$ (Table 2).

\section{Perioperative allogeneic transfusions}

Of the total 1289 patients, 500 patients (38.8\%) received perioperative RBC transfusions, 10\% (129/1289) of 


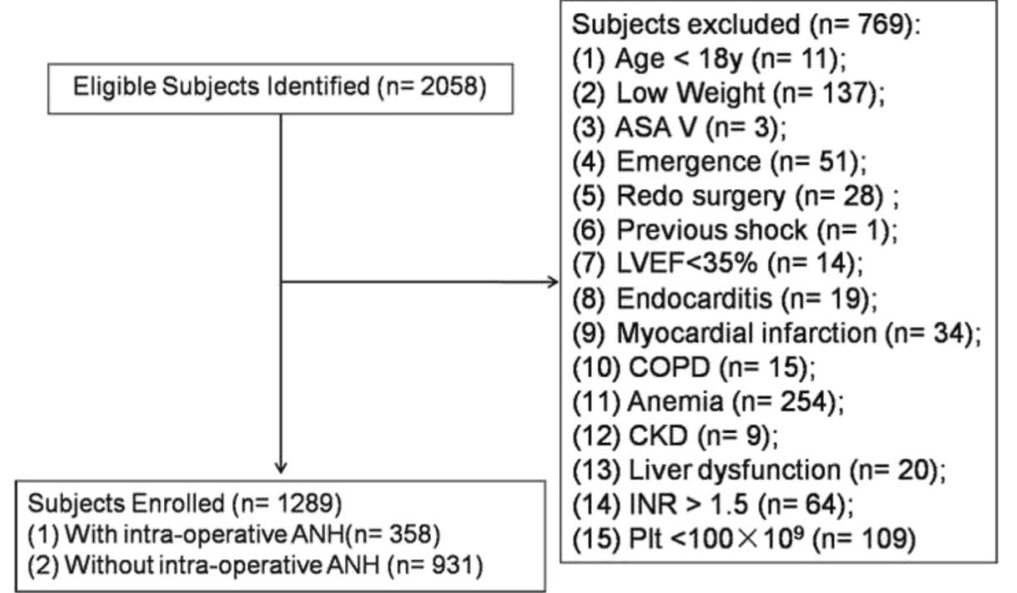

Fig. 1 Study population recruitment summary. LVEF = left ventricular ejection fraction; COPD = chronic obstructive pulmonary disease; CKD= chronic kidney disease; INR = international normalized ratio; PIt = platelet count; $\mathrm{ANH}=$ acute normovolemic hemodilution

patients received platelet, $56.4 \%(727 / 1289)$ of patients received FFP transfusions. Compared to the non-ANH group, the intraoperative $\mathrm{RBC}$ transfusions rate $(8.5 \% \mathrm{vs}$. $14.4 \% ; p=0.013)$ and number of RBC units $(p=0.019)$ decreased significantly in the ANH group. However, there was no significant difference regarding intraoperative hemostatic drugs, FFP and platelet concentrate transfusions, as well as postoperative and total perioperative allogeneic transfusions (Table 3 ).

\section{Postoperative outcomes after propensity matching}

Eighteen of the total 1289 patients (1.4\%) died during hospitalization, of which died in the operating room were four. Patients who died in the operating room after propensity matching were excluded from the postoperative outcomes analysis $(n=2)$. Patients who had preexisting renal dysfunction (serum creatinine level $>124 \mu \mathrm{mol} / \mathrm{L}$ for women and $>141 \mu \mathrm{mol} / \mathrm{L}$ for men or requiring renal replacement therapy) were excluded from the AKI analysis $(n=52)$ and patients with a preexisting history of AF were excluded from the AF analysis after propensity score matching $(n=161)$.

None of the patients experienced pulmonary embolism. Approximately $8.9 \%(115 / 1289)$ of patients developed postoperative pulmonary infection during hospitalization. The rate of pulmonary infection (6.8 vs. $11.3 \% ; p=0.036)$ was significantly declined in the ANH group as compared to that in the non-ANH group. No differences were found in the incidence of mortality, prolonged wound healing, stroke, AF, reoperation for postoperative bleeding and AKI between the two groups. There was also no difference in postoperative ventilation time, length of ICU and hospital stay (Table 4).

\section{Discussion}

In our retrospective analysis of patients undergoing cardiac surgery with $\mathrm{CPB}$, we found that mild volume $\mathrm{ANH}$ was associated with decreased intraoperative RBC transfusions rate and number of RBC units after data adjustment for preoperative risk factors. However, there was no significant difference regarding postoperative and total perioperative allogeneic transfusions. Our results further supported previous findings that the use of $\mathrm{ANH}$ could reduce intraoperative $\mathrm{RBC}$ transfusions in patients undergoing cardiac surgery $[6,7,21]$, even though blood loss was similar between the ANH and non-ANH groups in our study. Some meta-analysis also supported that ANH is effective in minimizing blood transfusion in patients undergoing cardiac surgery $[15,22]$.

However, the utility of mild volume $\mathrm{ANH}$ in reducing allogeneic blood transfusions in cardiac surgery is still controversial. Several studies have proved that mild volume ANH was not effective in reducing the number of allogeneic erythrocytes units $[8,23]$, but others have proven otherwise [6]. Our results support the positive finding that mild volume ANH could reduce intraoperative blood transfusions. The variations in blood saving strategy and surgery type may be the major reasons for our finding being different from other studies. Although Valter Casati et al.'s study did not find positive efficacy of low-volume ANH [8], we noticed that there was a decreasing trend of intraoperative $\mathrm{RBC}$ transfusions in the ANH group compared to non-ANH group (4.9\% vs. $7 \%$ ). Another potential reason was that their case mix was easier (over $50 \%$ were single valve surgeries), which leads to less blood loss and transfusions. However, more than $38.7 \%$ of the surgeries in our cohort were complex cardiac and aortic surgeries, resulting in that more patients required intraoperative $\mathrm{RBC}$ transfusions in both the 
Table 2 Operative Characteristics

\begin{tabular}{|c|c|c|c|}
\hline \multirow[t]{2}{*}{ Characteristics } & \multicolumn{2}{|l|}{ ANH } & \multirow[b]{2}{*}{$p$-value } \\
\hline & $\begin{array}{l}\text { Yes } \\
(n=354)\end{array}$ & $\begin{array}{l}\text { No } \\
(n=354)\end{array}$ & \\
\hline ANH [mean (SD); mL] & $342 \pm 138$ & & \\
\hline \multicolumn{4}{|l|}{ Operative Characteristics } \\
\hline Intra-aortic balloon pump, no. (\%) & $1(0.3 \%)$ & $1(0.3 \%)$ & 1.000 \\
\hline $\begin{array}{l}\text { Duration of anesthesia } \\
\text { [mean (SD); min] }\end{array}$ & $297 \pm 98$ & $305 \pm 110$ & 0.325 \\
\hline $\begin{array}{l}\text { Duration of surgery } \\
\text { [mean }(\mathrm{SD}) ; \mathrm{min}]\end{array}$ & $252 \pm 89$ & $260 \pm 110$ & 0.244 \\
\hline CPB time [mean (SD); min] & $125 \pm 59$ & $129 \pm 63$ & 0.399 \\
\hline Type of surgery, no. (\%) & & & 0.168 \\
\hline CABG & $23(6.5 \%)$ & $30(8.5 \%)$ & \\
\hline Valve surgery & $137(38.7 \%)$ & $121(34.2 \%)$ & \\
\hline Complex cardiac surgery & $116(32.8 \%)$ & $126(35.6 \%)$ & \\
\hline Aortic surgery & $24(6.8 \%)$ & $13(3.7 \%)$ & \\
\hline Others surgery & $54(15.3 \%)$ & $64(18.1 \%)$ & \\
\hline \multicolumn{4}{|l|}{ Input and Output } \\
\hline Blood loss [mean (SD); mL] & $684 \pm 355$ & $678 \pm 514$ & 0.855 \\
\hline Urine output [mean (SD); mL] & $788 \pm 465$ & $730 \pm 419$ & 0.084 \\
\hline Pump blood [mean (SD); mL] & $512 \pm 129$ & $508 \pm 139$ & 0.708 \\
\hline Cell salvage [median (SD); mL] & $375 \pm 267$ & $369 \pm 343$ & 0.797 \\
\hline $\begin{array}{l}\text { Intraoperative cristalloids and } \\
\text { colloids [mean (SD); mL] }\end{array}$ & $2272 \pm 610$ & $2140 \pm 770$ & 0.011 \\
\hline \multicolumn{4}{|l|}{ Hemostatic drugs Characteristics } \\
\hline Tranexamic Acid, no. (\%) & $121(34.2 \%)$ & $113(31.9 \%)$ & 0.523 \\
\hline $\begin{array}{l}\text { Prothrombin Complex } \\
\text { Concentrate, no. (\%) }\end{array}$ & $6(1.7 \%)$ & $7(20 \%)$ & 0.780 \\
\hline $\begin{array}{l}\text { Fibrinogen concentrate, } \\
\text { no. (\%) }\end{array}$ & $6(1.7 \%)$ & $10(2.8 \%)$ & 0.312 \\
\hline $\begin{array}{l}\text { Recombinant activated } \\
\text { factor VII, no. (\%) }\end{array}$ & $1(0.3 \%)$ & $3(0.8 \%)$ & 0.624 \\
\hline \multicolumn{4}{|l|}{ Arterial blood gas analysis } \\
\hline $\begin{array}{l}\text { Calcium content Pre-CPB } \\
\text { [mean (SD); mmol/L] }\end{array}$ & $1.08 \pm 0.10$ & $1.08 \pm 0.09$ & 0.871 \\
\hline Blood pH Pre-CPB [mean (SD)] & $7.40 \pm 0.06$ & $7.39 \pm 0.05$ & 0.636 \\
\hline Hct Pre-CPB [mean (SD);\%] & $38 \pm 5$ & $40 \pm 5$ & $<0.001$ \\
\hline $\begin{array}{l}\text { Calcium content End } \pm \mathrm{CPB} \\
{[\text { mean }(\mathrm{SD}) ; \mathrm{mmol} / \mathrm{L}]}\end{array}$ & $0.90 \pm 0.13$ & $0.87 \pm 0.13$ & 0.086 \\
\hline Blood pH End-CPB [mean (SD)] & $7.48 \pm 0.08$ & $7.50 \pm 0.09$ & 0.055 \\
\hline Hct End-CPB [mean (SD);\%] & $25 \pm 4$ & $27 \pm 5$ & 0.003 \\
\hline
\end{tabular}

Table 2 Operative Characteristics (Continued)

\begin{tabular}{llll}
\hline Calcium content Post \pm CPB & $1.03 \pm 0.17$ & $1.02 \pm 0.15$ & 0.628 \\
[mean (SD); mmol/L] & & & \\
Blood pH Post-CPB [mean (SD)] & $7.37 \pm 0.07$ & $7.38 \pm 0.08$ & 0.168 \\
Hct Post \pm CPB [mean (SD);\%] & $29 \pm 4$ & $30 \pm 5$ & 0.021
\end{tabular}

\#: Fisher's exact test was used; $C P B$ cardiopulmonary bypass, CABG coronary
artery bypass grafting, Valve surgery aortic, mitral and tricuspid valve surgery without ascending aortic replacement, Complex cardiac surgery combined coronary artery bypass graft surgery and valve surgery or multi-valve surgery, Aortic surgery aortic dissections, type $\mathrm{A}$ and $\mathrm{B}$, thoracic aortic aneurysms) or Aortic valve surgery with ascending aortic replacement; Others surgery type including atrial septal defect, interventricular septal defect, atrial myxoma, Aneurysm Sinus Valsalva, coronary artery pulmonary artery fistula, patent foramen ovale/atrial septal aneurysm surgery, and surgery for cardiac tumors, Pumped blood blood recovered from the extracorporeal circuit system, CPB cardiopulmonary bypass, $\mathrm{Hb}$ hemoglobin, $\mathrm{Hct}$ hematocrit, Pre-CPB before CPB and after performing $A N H$, End-CPB at the end of CPB, Post-CPB 30 min after CPB

ANH and non-ANH groups (8.5 and 14.4\%). Another point to be noted is that the cell saver technique was routinely applied in our study as a previous study reported that combination of cell saver with ANH produced better blood saving effect than ANH alone [24]. Another previous study of Alireza Mahoori et al. on exclusively elective coronary artery bypass graft (CABG) surgery patients [6] found that mild volume ANH could decrease requirements of total perioperative RBC transfusions. We failed to observe the similar positive effect of mild volume ANH on total perioperative RBC transfusions, this variation may mainly due to the different volumes of blood removed (342 vs. $490 \mathrm{~mL}$ ) and transfusion triggered criteria between our study and Alireza Mahooris study (hemoglobin concentration $<6-7 \mathrm{~g} / \mathrm{dL}$ vs. $<10 \mathrm{~g} / \mathrm{dL}$ ). The less strict transfusion triggered criteria in Alireza Mahooris study may lead to more transfusions rate compared to our cohort (57\% vs. $27 \%$ ).

Although ANH has been proved to reduce postoperative allogenic blood transfusions during cardiac surgery [7], our study failed to show these positive findings. A comprehensive blood saving strategy including antifibrinolytic agent [25] and TEG [26] has been applied and was demonstrated to reduce transfusion requirements. Thus the evidence of ANH may be less effective. The mild volume of ANH may also contribute to the less beneficial blood conservation effect, as Joshua Goldberg found that the reduction in allogeneic transfusions is more significant with greater volume ANH $(\geq 800 \mathrm{~mL})$ in cardiac surgery [7].

There is not much evidence regarding clinical outcome benefits of mild ANH in patients undergoing cardiac surgery. A recent article found that ANH was related to improved outcomes including renal failure, 30-day mortality, and length of hospital stay [7], and moderate ANH provided further cardioprotective effects during cardiac surgery $[13,14]$. However, some other authors mentioned that greater hemodilution might be associated with adverse complications, especially in patients with preexisting coronary disease [27]. In another study of patients undergoing 
Table 3 Perioperative allogeneic transfusions

\begin{tabular}{|c|c|c|c|}
\hline \multirow[t]{3}{*}{ Allogeneic transfusions } & \multicolumn{2}{|c|}{ Propensity-matched } & \multirow{3}{*}{$p$-value } \\
\hline & ANH & Non-ANH & \\
\hline & $(n=354)$ & $(n=354)$ & \\
\hline \multicolumn{4}{|l|}{ Intra-operative transfusion } \\
\hline RBC transfusion, no. (\%) & $30(8.5 \%)$ & $51(14.4 \%)$ & 0.013 \\
\hline Total RBCs transfusion $(U)$ & 164 & 289 & 0.019 \\
\hline FFP transfusion, no. (\%) & $96(27.1 \%)$ & $109(30.8 \%)$ & 0.281 \\
\hline Total FFP transfusion (ml) & 63770 & 78660 & 0.225 \\
\hline Platelet transfusion, no. (\%) & $25(7.1 \%)$ & $18(5.1 \%)$ & 0.271 \\
\hline Total Platelet transfusion $(U)$ & 261 & 205.7 & 0.432 \\
\hline \multicolumn{4}{|l|}{ Postoperative RBCs transfusion } \\
\hline Postoperative in 24 h, no. (\%) & $72(20.4 \%)$ & $63(17.8 \%)$ & 0.389 \\
\hline $\begin{array}{l}\text { Postoperative in } 24 \mathrm{~h} \\
\text { [median (IQR); U] }\end{array}$ & $0(0$ to 0$)$ & $0(0$ to 0$)$ & 0.407 \\
\hline$>24$ h after surgical start, no. (\%) & $24(6.8 \%)$ & $25(7.1 \%)$ & 0.882 \\
\hline $\begin{array}{l}>24 \mathrm{~h} \text { after surgical start } \\
\text { [median (IQR); U] }\end{array}$ & $0(0$ to 0$)$ & $0(0$ to 0$)$ & 0.881 \\
\hline \multicolumn{4}{|l|}{ Postoperative FFP transfusion } \\
\hline Postoperative in 24 h, no. (\%) & $90(25.5 \%)$ & $93(26.3 \%)$ & 0.797 \\
\hline $\begin{array}{l}\text { Postoperative in } 24 \mathrm{~h} \\
\text { [median (IQR); ml] }\end{array}$ & 0 (0 to 230$)$ & 0 (0 to 200$)$ & 0.914 \\
\hline Postoperative after 24 h, no. (\%) & $7(2.0 \%)$ & $7(2.0 \%)$ & 1.000 \\
\hline $\begin{array}{l}>24 \mathrm{~h} \text { after surgical start } \\
\text { [median (IQR); ml] }\end{array}$ & $0(0$ to 0$)$ & $0(0$ to 0$)$ & 0.996 \\
\hline \multicolumn{4}{|l|}{ Postoperative Platelet transfusion } \\
\hline Postoperative in 24 h, no. (\%) & $10(2.8 \%)$ & $9(2.5 \%)$ & 0.816 \\
\hline $\begin{array}{l}\text { Postoperative in } 24 \mathrm{~h} \\
\text { [median (IQR); U] }\end{array}$ & $0(0$ to 0$)$ & $0(0$ to 0$)$ & 0.802 \\
\hline Postoperative after 24 h, no. (\%) & $1(0.3 \%)$ & $2(0.6 \%)$ & $0.624 \#$ \\
\hline $\begin{array}{l}>24 \mathrm{~h} \text { after surgical start } \\
\text { [median (IQR); U] }\end{array}$ & $0(0$ to 0$)$ & $0(0$ to 0$)$ & 0.561 \\
\hline \multicolumn{4}{|c|}{ Total Perioperative Allogeneic transfusions } \\
\hline RBC transfusion, no. (\%) & $98(27.7 \%)$ & $96(27.1 \%)$ & 0.866 \\
\hline RBCs transfusion $(U)$ & $0(0$ to 2$)$ & $0(0$ to 2$)$ & 0.300 \\
\hline FFP transfusion, no. (\%) & $153(43.2 \%)$ & $157(44.4 \%)$ & 0.762 \\
\hline FFP transfusion (ml) & 0 (0 to 730$)$ & $0(0$ to 630$)$ & 0.876 \\
\hline Platelet transfusion, no. (\%) & $35(9.9 \%)$ & $28(7.9 \%)$ & 0.355 \\
\hline Platelet transfusion (U) & $0(0$ to 0$)$ & $0(0$ to 0$)$ & 0.380 \\
\hline Postoperative HCT [median (SD); \%] & $32 \pm 5$ & $32 \pm 4$ & 0.464 \\
\hline
\end{tabular}

$R B C$ s red blood cells, FFP fresh frozen plasma, $H C T$ hematocrit, $A N H$ acute normovolemic hemodilution

pancreaticoduodenectomy, ANH did not seem to decrease blood transfusions, but lead to more pancreatic anastomotic complications for greater intraoperative fluid administration [28]. Some authors criticize ANH for the possibly of causing perioperative adverse outcomes including damaged pulmonary function for increased lung fluid volume [8]. Furthermore, a recent study even found that after
Table 4 Postoperative outcomes $(n=354)$

\begin{tabular}{|c|c|c|c|}
\hline \multirow[t]{2}{*}{ Outcomes } & \multicolumn{2}{|c|}{ Propensity-matched } & \multirow[b]{2}{*}{$p$ valve } \\
\hline & ANH & Non-ANH & \\
\hline \multicolumn{4}{|l|}{ Pulmonary infection } \\
\hline no & $329(93.2 \%)$ & $313(88.7 \%)$ & \\
\hline yes & $24(6.8 \%)$ & $40(11.3 \%)$ & 0.036 \\
\hline \multicolumn{4}{|l|}{ Death } \\
\hline no & $350(99.2 \%)$ & $351(99.4 \%)$ & \\
\hline yes & $3(0.8 \%)$ & $2(0.6 \%)$ & $1.000 \#$ \\
\hline \multicolumn{4}{|l|}{ Prolonged wound healing } \\
\hline no & $332(94.1 \%)$ & $341(96.6 \%)$ & \\
\hline yes & $21(5.9 \%)$ & $12(3.4 \%)$ & 0.109 \\
\hline \multicolumn{4}{|l|}{ Stroke } \\
\hline no & $352(99.7 \%)$ & $350(99.2 \%)$ & \\
\hline yes & $1(0.3 \%)$ & $3(0.8 \%)$ & $0.624 \#$ \\
\hline \multicolumn{4}{|l|}{ AF } \\
\hline no & $237(86.8 \%)$ & $233(85.7 \%)$ & \\
\hline yes & $36(13.2 \%)$ & $39(14.3 \%)$ & 0.696 \\
\hline \multicolumn{4}{|c|}{ Resternotomy for postoperative bleeding } \\
\hline no & $349(98.9 \%)$ & $350(99.2 \%)$ & \\
\hline yes & $4(1.1 \%)$ & $3(0.8 \%)$ & $1.000 \#$ \\
\hline \multicolumn{4}{|l|}{ AKI } \\
\hline no & $245(74.0 \%)$ & $241(74.6 \%)$ & \\
\hline yes & $86(26.0 \%)$ & $82(25.4 \%)$ & 0.862 \\
\hline Stage1 & $63(73.3 \%)$ & 59 (71.9\%) & \\
\hline Stage2 & $15(17.4 \%)$ & $18(22.0 \%)$ & \\
\hline Stage3 & $8(9.3 \%)$ & $5(6.1 \%)$ & \\
\hline Ventilation [mean (SD); hours] & $17 \pm 21$ & $19 \pm 29$ & 0.239 \\
\hline ICU [mean (SD); days] & $4.4 \pm 2.4$ & $4.2 \pm 3.1$ & 0.254 \\
\hline LOS [mean (SD); days] & $12 \pm 9$ & $12 \pm 10$ & 0.708 \\
\hline
\end{tabular}

$A F$ atrial fibrillation, $A K I$ acute kidney injury, $A N H$ acute normovolemic hemodilution, ICU intensive care unit, LOS length of hospital stay

moderate ANH, patients undergoing total hip arthroplasty showed a hypocoagulable state [29].

Although we did not observe the positive effect of ANH regarding mortality, stroke, $\mathrm{AF}, \mathrm{AKI}$, and resternotomy for postoperative bleeding, our findings suggest that mild volume ANH might be associated with lower incidence of pulmonary infection. Some possible mechanisms may contribute to this protective effect. First, the indirect effect of reducing the rate of $\mathrm{RBC}$ transfusions may improve outcomes. RBC transfusions could increase postoperative pneumonia in patients undergoing CABG surgery [17]. Second, ANH blood was associated with a smaller concentration of inflammatory mediators such as interleukin10 and neutrophil elastase than predonated autologous blood [30]. Third, due to the hemodilution-induced blood viscosity, such protection might be associated with an improved oxygen supply-consumption balance [14]. More 
evidence is needed to confirm the positive effect of mild volume ANH on cardiac surgery outcomes, including pulmonary complication.

\section{Limitations}

There were some limitations in this study. Firstly, due to clear and strict indications, ANH [2] could not be performed widely for all paitents. Secondly, although the strict exclusion criteria and propensity score adjustment were assumed to minimize biases, the potential bias factors may not be completely eliminated in a retrospective study. Thirdly, although no significant difference was observed between the two matched groups regarding intraoperative tranexamic acid adminstration, the administration of tranexamic acid was not absolutely unified in this study. Finally, population characteristics and the blood saving strategy were different for each institution; hence, caution should be used when interpreting our findings.

\section{Conclusions}

In conclusion, in our large retrospective study, mild volume ANH was associated with lower intraoperative RBC transfusions and postoperative pulmonary infection in Chinese patients undergoing cardiac surgery. However, there was no significant difference regarding postoperative and total perioperative allogeneic transfusions. Further prospective and randomized studies are needed to confirm the effects of mild volume ANH on perioperative outcomes during cardiac surgery.

\section{Additional file}

Additional file 1: Study Data Information. Description of data: Details of 1289 adult patients underwent cardiac surgeries with CPB from January 1 , 2010, to December 31, 2015 after excluding those who were unsuitable for performing ANH (XLS $1175 \mathrm{~kb})$

\section{Abbreviations}

AF: Atrial fibrillation; AKI: Acute kidney injury; ALB: Albumin; ANH: Acute normovolemic hemodilution; aPTT: Activated partial prothrombin time; ASA: American standards association; CKD: Chronic kidney disease; COPD: Chronic obstructive pulmonary disease; CPB: Cardiopulmonary bypass; Cr: Creatinine; Fb: Fibrinogen concentrate; FFP: Fresh frozen plasma; IABA: Intra-aortic balloon pump; ICU: Intensive care unit; INR: International normalized ratio; LOS: Length of hospital stay; LVEF: Left ventricular ejection fraction; RBC: Red blood cells; rVlla: Recombinant factor VII;

TEE: Transesophageal echocardiography; TEG: Thrombelastography

\section{Acknowledgements}

We thank Yun-xian YU (Department of Epidemiology and Health Statistics, School of Public Health, Zhejiang University) who provided statistical analyze assistance.

\section{Funding}

No funding was received.

\section{Availability of data and materials}

All data analysed during this study are included in this published article [Additional file 1].

\section{Authors' contributions}

All authors have seen the manuscript and approved to submit to your journal. ZZF and YM designed the study. JXP, ZFJ, YLN and XT did the work of data collecting, and data was analysed by SK. ZZF and YM wrote the paper.

\section{Competing interests}

The authors declare that they have no competing interests.

\section{Consent for publication}

Not applicable.

Ethics approval and consent to participate

This retrospective study was approved by the Ethics Committee of Zhejiang University (Hangzhou, China; No.2016-021), with patient consent waived.

\section{Author details}

'Department of Anesthesiology, Second Affiliated Hospital, School of Medicine, Zhejiang University, Zhejiang Province, China. ${ }^{2}$ Department of Anesthesiology, The Affiliated Yiwu Hospital of Wenzhou Medical University, Yiwu, China

Received: 6 October 2016 Accepted: 17 January 2017

Published online: 26 January 2017

References

1. Xue R, Chen Y, Wen J. Blood shortages and donation in China. Lancet. 2016:387:1905.

2. Ferraris VA, Brown JR, Despotis GJ, Hammon JW, Reece TB, Saha SP, et al. 2011 update to the Society of Thoracic Surgeons and the Society of Cardiovascular Anesthesiologists blood conservation clinical practice guidelines. Ann Thorac Surg. 2011;91:944-82.

3. Rogers MA, Blumberg N, Saint S, Langa KM, Nallamothu BK. Hospital variation in transfusion and infection after cardiac surgery: a cohort study. BMC Med. 2009:7:37.

4. Snyder-Ramos SA, Möhnle P, Weng YS, Böttiger BW, Kulier A, Levin J, et al. The ongoing variability in blood transfusion practices in cardiac surgery. Transfusion. 2008:48:1284-99.

5. Nozohoor S, Johnsson P, Scicluna S, Wallentin P, Andell E, Nilsson J. A casecontrolled evaluation of the Medtronic Resting Heart System compared with conventional cardiopulmonary bypass in patients undergoing isolated coronary artery bypass surgery. Interact Cardiovasc Thorac Surg. 2012;14:599-604

6. Mahoori A, Heshmati F, Noroozinia H, Mehdizadeh H, Salehi S, Rohani M. Intraoperative minimal acute normovolemic hemodilution in patients undergoing coronary artery bypass surgery. Middle East J Anaesthesiol. 2009:20:423-9

7. Goldberg J, Paugh TA, Dickinson TA, Fuller J, Paone G, Theurer PF, et al. Greater Volume of Acute Normovolemic Hemodilution May Aid in Reducing Blood Transfusions After Cardiac Surgery. Ann Thorac Surg. 2015;100:1581-7. discussion 1587.

8. Casati V, Speziali G, D'Alessandro C, Cianchi C, Antonietta Grasso M, Spagnolo S, et al. Intraoperative low-volume acute normovolemic hemodilution in adult open-heart surgery. Anesthesiology. 2002;97:367-73.

9. Curley GF, Shehata N, Mazer CD, Hare GM, Friedrich JO. Transfusion triggers for guiding RBC transfusion for cardiovascular surgery: a systematic review and meta-analysis*. Crit Care Med. 2014;42:2611-24.

10. Gillon J, Thomas MJ, Desmond MJ. Consensus conference on autologous transfusion. Acute normovolaemic haemodilution. Transfusion. 1996;36:640-3.

11. Kahraman S, Altunkaya H, Celebioğlu B, Kanbak M, Paşaoğlu I, Erdem K. The effect of acute normovolemic hemodilution on homologous blood requirements and total estimated red blood cell volume lost. Acta Anaesthesiol Scand. 1997:41:614-7.

12. Grant MC, Resar LM, Frank SM. The Efficacy and Utility of Acute Normovolemic Hemodilution. Anesth Analg. 2015;121:1412-4.

13. Licker M, Sierra J, Kalangos A, Panos A, Diaper J, Ellenberger C. Cardioprotective effects of acute normovolemic hemodilution in patients with severe aortic stenosis undergoing valve replacement. Transfusion. 2007:47:341-50.

14. Licker M, Ellenberger C, Sierra J, Kalangos A, Diaper J, Morel D. Cardioprotective effects of acute normovolemic hemodilution in patients undergoing coronary artery bypass surgery. Chest. 2005;128:838-47. 
15. Zhou X, Zhang C, Wang Y, Yu L, Yan M. Preoperative Acute Normovolemic Hemodilution for Minimizing Allogeneic Blood Transfusion: A Meta-Analysis. Anesth Analg. 2015;121:1443-55.

16. Likosky DS, Paone G, Zhang M, Rogers MA, Harrington SD, Theurer PF, et al. Red Blood Cell Transfusions Impact Pneumonia Rates After Coronary Artery Bypass Grafting. Ann Thorac Surg. 2015;100:794-800. discussion 801.

17. Min JJ, Nam K, Kim TK, Kim HJ, Seo JH, Hwang HY, et al. Relationship between early postoperative C-reactive protein elevation and long-term postoperative major adverse cardiovascular and cerebral events in patients undergoing off-pump coronary artery bypass graft surgery: a retrospective study. Br J Anaesth. 2014;113:391-401.

18. Klinger RY, Thunberg CA, White WD, Fontes $\mathrm{M}$, Waldron NH, Piccini JP, et al. Intraoperative Magnesium Administration Does Not Reduce Postoperative Atrial Fibrillation After Cardiac Surgery. Anesth Analg. 2015;121:861-7.

19. Khwaja A. KDIGO clinical practice guidelines for acute kidney injury. Nephron Clin Pract. 2012;120:c179-84.

20. Austin PC. Balance diagnostics for comparing the distribution of baseline covariates between treatment groups in propensity-score matched samples. Stat Med. 2009;28:3083-107.

21. Goodnough LT. Autologous blood donation. Anesthesiol Clin North America. 2005;23:263-70. vi.

22. Bryson GL, Laupacis A, Wells GA. Does acute normovolemic hemodilution reduce perioperative allogeneic transfusion? A meta-analysis. The International Study of Perioperative Transfusion. Anesth Analg. 1998:86:9-15.

23. Virmani S, Tempe DK, Pandey BC, et al. Acute normovolemic hemodilution is not beneficial in patients undergoing primary elective valve surgery. Ann Card Anaesth. 2010;13:34-8.

24. Tempe D, Bajwa R, Cooper A, Nag B, Tomar AS, Khanna SK, et al. Blood conservation in small adults undergoing valve surgery. J Cardiothorac Vasc Anesth. 1996;10:502-6.

25. Ker K, Prieto-Merino D, Roberts I. Systematic review, meta-analysis and meta-regression of the effect of tranexamic acid on surgical blood loss. Br J Surg. 2013;100:1271-9.

26. Besser MW, Ortmann E, Klein AA. Haemostatic management of cardiac surgical haemorrhage. Anaesthesia. 2015;70:87-95. e29-31.

27. IckX BE, Rigolet M, Van Der Linden PJ. Cardiovascular and metabolic response to acute normovolemic anemia. Effects of anesthesia. Anesthesiology. 2000;93:1011-6.

28. Fischer M, Matsuo K, Gonen M, Grant F, Dematteo RP, D'Angelica MI, et al. Relationship between intraoperative fluid administration and perioperative outcome after pancreaticoduodenectomy: results of a prospective randomized trial of acute normovolemic hemodilution compared with standard intraoperative management. Ann Surg. 2010;252:952-8.

29. Shin HJ, Na HS, Do SH. The effects of acute normovolaemic haemodilution on peri-operative coagulation in total hip arthroplasty. Anaesthesia. 2015;70:304-9.

30. Kotake Y, Yamamoto M, Matsumoto M, Yamada T, Nagata H, Morisaki H, et al. Difference in autologous blood transfusion-induced inflammatory responses between acute normovolemic hemodilution and preoperative donation. J Anesth. 2009;23:61-6.

\section{Submit your next manuscript to BioMed Central and we will help you at every step:}

- We accept pre-submission inquiries

- Our selector tool helps you to find the most relevant journal

- We provide round the clock customer support

- Convenient online submission

- Thorough peer review

- Inclusion in PubMed and all major indexing services

- Maximum visibility for your research

Submit your manuscript at www.biomedcentral.com/submit

) Biomed Central 